\title{
Uma leitura econômica de $O$ cortiço, de Aluísio Azevedo
}

\author{
Vivaldo Andrade dos Santos ${ }^{1}$ e 2
}

\section{Resumo}

O ensaio faz uma releitura do romance $O$ cortiço, de Aluísio Azevedo, a partir da nova crítica econômica que tem despontado no campo da literatura nas últimas décadas. Interessa, em particular, trazer à luz o tema do desenvolvimento capitalista na ficção naturalista, de fins do século XIX, para pensar o momento atual da crise econômica contemporânea, que se deu em 2008, e cujo impacto ainda está presente entre nós. Destaca-se, neste ensaio, o tema da avareza, da ética, da confiança e da especulação - itens fundamentais na formação moral do personagem João Romão, enquanto parte de um projeto capitalista, impulsionador em simultâneo do projeto de modernidade.

\section{Palavras-chave}

Aluísio Azevedo, O cortiço, crítica econômica, dinheiro, capital, marxismo, naturalismo, ética, modernidade.

Recebido em 11 de outubro de 2011

Aprovado em 8 de dezembro de 2011

1 Professor associado de Literatura Brasileira, Georgetown University. E-mail: vas2@georgetown.edu

2 Agradeço à Profa. Doutora Isabel Capeloa Gil e ao CECC - Centro de Estudos de Comunicação e Cultura da Universidade Católica Portuguesa o convite para participar do congresso The Cultural Life of Money (2009), para o qual escrevi uma versão inicial deste ensaio, e por me permitirem submetê-lo para publicação, na sua forma traduzida, para a Revista do IEB. 


\title{
An Economic Reading of Aluísio Azevedo's $\boldsymbol{O}$ Cortiço
}

\author{
Vivaldo Andrade dos Santos
}

\section{Abstract}

This essay reexamines the novel $O$ cortico [The Slum], by Aluísio Azevedo, considering the new economic criticism, which has emerged in the field of literary studies in the last decades. The author of the article is interested in shedding light to the theme of capitalism development in the naturalist fiction, of the end of XIX century, to reflect on the present economical crisis that took place in 2008, and from which our society is still suffering its impact. The essay focuses on fundamental principles to the development of the novel's main character, João Romão, such as greed, ethics, trust, speculation, as part of a capitalist project, tied at the same time, to a project of modernity.

\section{Keywords}

Aluísio Azevedo, O cortico, economical criticism, money, capital, Marxism, ethics, naturalism, modernity. 


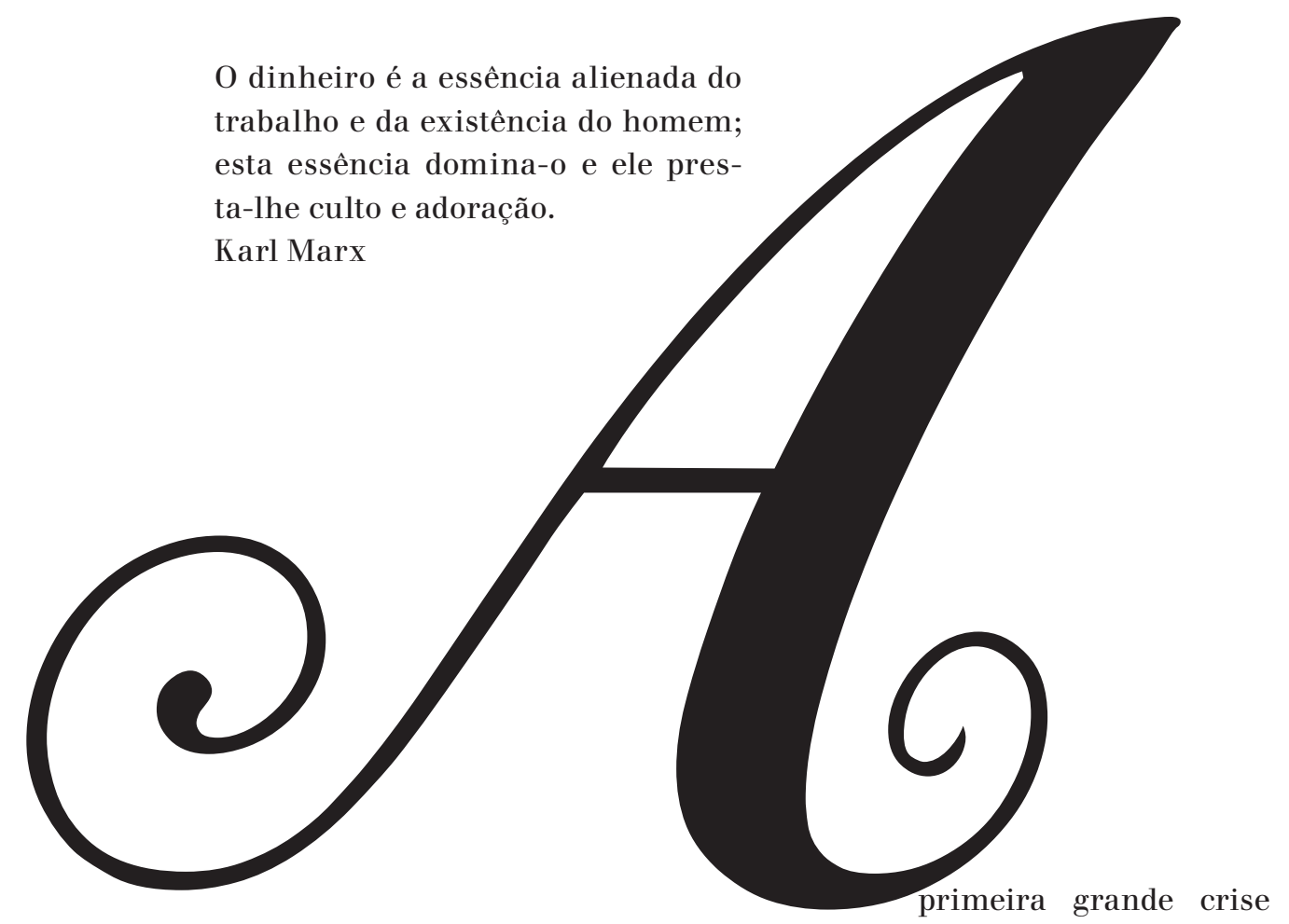

econômica do século XXI, que aconteceu no ano de 2008, trouxe de volta à cena a importância da economia na nossa vida cotidiana. A crise tem sido extraordinária, considerando-se o momento na história quando ela aconteceu e a dimensão dos seus efeitos, numa sociedade pós-industrial e num mundo contemporâneo globalizado. Na dinâmica do capitalismo o caráter extraordinário da crise é natural. A história do capitalismo mostra-nos como as crises econômicas forçam uma mudança e um reajuste nas práticas financeiras em vista do capital ${ }^{5}$. Do mesmo modo, a relação entre literatura e economia também não é novidade, como, talvez, um congresso interdisciplinar organizado em torno do tema do dinheiro, para o qual este artigo foi escrito, possa sugerir 4 .

Há um pouco mais de dez anos, Mark Osteen e Martha Woodmansee, professores de departamentos de Língua Inglesa, publicaram The new economic criticism: Studies at the intersection of literature and economics $(1999)^{5}$. Os organizadores do livro ressaltam um novo surgimento de uma

3 Ver a discussão sobre o tema em KINDLEBERGER, Charles Poor. Manias, panics and crashes: A history of financial crises. Hoboken, N. J.: John Wiley \& Sons, 2005.

4. Congresso The Cultural Life of Money, organizado pela Universidade Católica Portuguesa, Lisboa, 12-13 nov. 2009.

5 A semente do projeto nasceu de uma mesa sobre economia e literatura apresentada em 1991 durante o congresso da Midwest Modern Language Association (MMLA), seguido de um congresso sobre o mesmo tema, que deu origem a este livro.

revista ieb $n_{54} 2012$ set./mar. p. 53-66 
crítica econômica no campo intelectual dos anos 1990, uma continuação do que começou ao redor do final dos anos 1970 e começo dos anos 1980. A assim chamada Nova crítica econômica [The new economic criticism] estava ligada a um campo de pesquisa da crítica interessado em estudar a relação entre literatura, cultura e economia. De acordo com Osteen e Woodmansee, a explicação para o surgimento deste campo de pesquisa dentro dos estudos literários tem várias razões, principalmente: 1) a volta a uma abordagem historicista, distante da desconstrução, semiótica, e as tendências formalistas tradicionais que imperaram nos anos 1970 e começo dos anos 1980; 2) a crise na indústria editorial acadêmica e a procura por novas abordagens teóricas; 3 ) o influxo dos estudos culturais e sua ênfase em métodos de interdisciplinaridade, incluindo, neste caso, o trabalho dos economistas; 4) o lugar da economia na sociedade, tendo início nos anos 1980, acompanhado das discussões sobre bolsa de valores, juros, títulos, especulação, e assim por diante - os quais não se tinham observado em nossa sociedade desde a década de $1930^{6}$.

\section{A dinâmica do capital}

Este artigo analisa a visão do dinheiro e a dinâmica do capitalismo no romance $O$ cortiço, de Aluísio Azevedo ${ }^{7}$. Em resumo, o romance conta a história de João Romão, imigrante português avarento que herda uma pequena venda, compra uma pequena propriedade de terra e constrói um cortiço que começa a crescer dia após dia no subúrbio da cidade do Rio de Janeiro. A história de João Romão está ligada à do cortiço e às vidas dos seus habitantes. O romance de Azevedo deve ao naturalismo do século

6 OSTEEN, Mark.; WOODMANSEE, Martha. The new economic criticism: Studies at the intersection of literature and economics. London: Routledge, 1999. p. 3-4.

7 AZEVEDO, Aluísio. O cortiço. São Paulo: Martins, 1967. A maioria dos estudos sobre o O cortiço analisam a obra a partir da estética naturalista do período. O brilhante artigo de Antonio Candido, "De cortiço a cortiço", no qual o crítico faz uma leitura do romance como uma alegoria da sociedade brasileira no século XIX, é um dos primeiros estudos a ressaltar a questão econômica no romance de Azevedo. De acordo com o crítico, "Daí a pertinência com que Aluísio escolheu para objeto a acumulação do capital a partir das suas fases mais modestas e primárias, situando-a em relação estreita com a natureza física, já obliterada no mundo europeu do trabalho urbano. No seu romance o enriquecimento é feito à custa da exploração brutal do trabalho servil, da renda imobiliária arrancada do pobre, da usura e até do roubo puro e simples, constituindo o que se poderia qualificar de primitivismo econômico" (CANDIDO, Antonio. De cortiço a cortiço. Novos Estudos CEBRAP zo, 1991. p. 11z. Também no livro $O$ discurso e a cidade. Rio de Janeiro: Ouro sobre Azul, 2004). Um segundo artigo, ainda no prelo, trata do tema do capital no romance: "Zola in Rio de Janeiro: The production of space in Aluísio Azevedo's $O$ corti ço” (Portuguese Studies 26:2, forthcoming, 2010), de Lúcia Sá - a quem sou imensamente grato por sua generosidade em compartilhá-lo comigo para este ensaio. 
XIX, estética que procurou aplicar os princípios científicos à literatura. $O$ cortiço, altamente influenciado pela obra de Émile Zola, procura provar que todo indivíduo é governado pelos instintos e paixões, bem como seu caráter e moral são definidos pelo instinto hereditário e pelo meio ambiente no qual ele vive ${ }^{8}$.

$O$ cortiço conta a história de João Romão e sua ambição de enriquecer. No romance, João Romão é um personagem para quem nenhuma concepção ética ou moral impede seu desejo de acumulação capitalista. Depois de trabalhar desde os 13 até os 25 anos para um vendeiro no bairro de Botafogo no Rio de Janeiro, que lhe deixou, após se aposentar, para compensar os anos de pagamentos atrasados, a venda e um conto e quinhentos em dinheiro, João Romão:

Proprietário e estabelecido por sua conta, o rapaz atirou-se à labutação ainda com mais ardor, possuindo-se de tal delírio de enriquecer, que afrontava resignado as mais duras privações. Dormia sobre o balcão da própria venda, em cima de uma esteira, fazendo travesseiro de um saco de estopa cheio de palha. A comida arranjava-lha, mediante quatrocentos réis por dia, uma quitandeira sua vizinha, a Bertoleza, crioula trintona, escrava de um velho cego (...). ${ }^{9}$

A cena inicial do romance de Azevedo antecipa ao leitor o que seria a motivação da vida de João Romão. Mais do que qualquer descrição física, a primeira apresentação do protagonista do romance é sua pulsão mental: sua mania por ser rico, seu "delírio de enriquecer". No universo de João Romão, toda ação visa ao crescimento econômico, no qual o dinheiro é o único objeto de desejo. De fato, acumulação equipara-se a privação: "apertando cada vez mais as próprias despesas, empilhando privações sobre privações". Privação traduz-se em ascetismo, como observa Marx, "The cult of money has its asceticism, its self-denial, its self-sacrifice - economy and frugality, contempt for mundane, temporal and fleeting pleasures; the chase after the eternal treasure"10. A procura do "tesouro eterno" que o dinheiro representa no romance traduz-se não somente na privação individual das coisas materiais ou em trabalhar sete dias por semana ("como uma junta de bois" ${ }^{11}$ com sua sócia-esposa, negra e ex-escrava Bertoleza), mas até mesmo em furtos e roubos:

8 Ver CANDIDO, Antonio. De cortiço a cortiço. op. cit.; e SÁ, Lúcia. Zola in Rio de Janeiro: The production of space in Aluísio Azevedo's O cortiço. op. cit.

9 AZEVEDO, Aluísio. O cortico. op. cit. p. 19.

10 MARX, Karl. Grundrisse: Foundations of the critique of political economy (Rough draft). Translated by Martin Nicolaus. New York: Penguin Books, 1973. p. $23^{2}$.

11 AZEVEDO, Aluísio. op. cit. p. 4.

revista ieb $n_{54} 2012$ set./mar. p. 53-66 
Sempre em mangas de camisa, sem domingo nem dia santo, não perdendo nunca a ocasião de assenhorear-se do alheio, deixando de pagar todas as vezes que podia e nunca deixando de receber, enganando os fregueses, roubando nos pesos e nas medidas, comprando por dez réis de mel coado o que os escravos furtavam da casa dos seus senhores (...). ${ }^{12}$

O dinheiro como o objeto da avareza, segundo Marx, é diferente do desejo por "clothes, weapons, jewels, women, wine etc.", formas particularizadas do desejo. Como avareza, "money is there as not only the object but also the fountainhead of greed"13. Do ponto de vista do dinheiro como avareza, a vontade de João Romão por essas formas individualizadas do desejo é, em essência, motivada pelo dinheiro como forma transcendente do desejo imediato. Neste sentido, João Romão distancia-se daquilo que é satisfação imediata do corpo. Conforto como uma cama ou um travesseiro e comida são recusados com intuito de acumulação de riqueza:

Desde que a febre de possuir se apoderou dele totalmente, todos os seus atos, todos, fosse o mais simples, visavam um interesse pecuniário. Só tinha uma preocupação: aumentar os bens. Das suas hortas recolhia para si e para a companheira os piores legumes, aqueles que, por maus, ninguém compraria; as suas galinhas produziam muito e ele não comia um ovo, do que no entanto gostava imenso; vendia-os todos e contentava-se com os restos da comida dos trabalhadores. Aquilo já não era ambição, era uma moléstia nervosa, uma loucura, um desespero de acumular; de reduzir tudo a moeda..$^{14}$

O romance dramatiza o processo de acumulação econômica ligado não somente ao valor moral ou ético, mas também ao engano e à falsificação, à fraude:

Afinal, já lhe não bastava sortir o seu estabelecimento nos armazéns fornecedores; começou a receber alguns gêneros diretamente da Europa: o vinho, por exemplo, que ele dantes comprava aos quintos nas casas de atacado, vinha-lhe agora de Portugal às pipas, e de cada uma fazia três com água e cachaça; e despachava faturas de barris de

12 Idem, ibidem, p. 25.

13 MARX, Karl. Grundrisse. op. cit. p. 222.

14 AZEVEDO, Aluísio. op. cit. p. zı.

58

revista ieb $\quad n 54 \quad 2012$ set./mar. p. 53-66 
manteiga, de caixas de conserva, caixões de fósforos, azeite, queijos, louça e muitas outras mercadorias. ${ }^{15}$

João Romão imagina uma economia na qual ele tem controle absoluto sobre a máquina econômica. Apesar de ser contra o intermediário, João Romão não tem nenhum interesse em fazer ecoar o que poderiam ser as preocupações dos produtores com o sistema capitalista. Ao contrário, ele se vê como a única ponte entre os produtores e o mercado. Como um mestre em finanças, João Romão nada mais é que aquele "who has produced nothing, over production and over the product. Just as he estranges himself from his own activity, so he confers ownership to a stranger over this activity which does not really belong to him", como afirma Marx no seu livro Economic and philosophic manuscripts of $1844^{16}$.

Segundo o narrador, a ação de João Romão não tem nenhuma relação com a ambição econômica; é, na realidade, "uma moléstia nervosa, uma loucura, um desespero de acumular; de reduzir tudo a moeda”. Do ponto de vista do pensamento materialista, o Naturalismo não dispõe das ferramentas necessárias para entender as motivações de João Romão e falha na sua limitação científica. Nesse sentido, relembremos Marx, para quem a cobiça não é uma doença ou um comportamento natural, mas sim, antes de tudo, histórica: "The mania for possessions is possible without money; but greed itself is the product of a definite social development, not natural, as opposed to historical"17. Marx argumenta que este conceito de cobiça está ligado ao fim da tradição, à "queda das comunidades antigas".

$\mathrm{O}$ autor de $O$ capital argumenta que, desde o momento em que o dinheiro se desenvolve além das suas funções no comércio e na circulação, o dono do dinheiro, o indivíduo, perde sua individualidade em consideração ao aumento das forças de produção, mais conhecido como o processo industrial. Marx vê o dinheiro ligado ao "developed moment of production only where and when wage labor exists". Paradoxalmente, se o dinheiro é visto como destruidor das antigas comunidades, ele é ao mesmo tempo transformador da formação social, tornando-se " a condition for its development and a driving-wheel for the development of all forces of production, material and mental"18. Para Marx, com a dissolução do indivíduo nesse novo processo econômico, a cobiça como um impulso individual é substituída por uma cobiça geral ["the urge of all”] de se fazer dinheiro sob as

15 Idem, ibidem, p. $3^{2}$.

16 MARX, Karl. Economic and philosophic manuscripts of 1844 . Disponível em: < http://Www. wsu.edu:8o8o/ dee/MODERN/ALIEN.HTM>. Acesso em 5 jul. 2010.

17 MARX, Karl. Grundrisse. op. cit. p. 222.

18 Idem, ibidem, p. 223.

59

revista ieb $\quad n 54 \quad 2012$ set./mar. p. 53-66 
condições de trabalho assalariado, tornando-se assim um tipo de riqueza autorreprodutiva ["self-reproducing wealth"] ${ }^{19}$.

A crítica muitas vezes não viu esse ponto no romance de Azevedo, por focar insistentemente na personalidade de João Romão, sem perceber que as ações do personagem são parte do desenvolvimento capitalista, como já adiantou Candido. Na verdade, seu plano de se amasiar com Bertoleza, fingindo que a estava libertando da escravidão, é ilustrativo disso. Para Bertoleza, João Romão representa a promessa de salvação, amor e liberdade; no entanto, o relacionamento para ele nada mais é do que uma forma de importância monetária ${ }^{20}$. Se João Romão liberta Bertoleza, por juntar-se com ela, ele a torna sua empregada na lógica capitalista. O fim da escravidão abre, assim, espaço para o sujeito livre no processo de produção que João Romão representa:

Daí em diante, João Romão tornou-se o caixa, o procurador e o conselheiro da crioula. No fim de pouco tempo era ele quem tomava conta de tudo que ela produzia e era também quem punha e dispunha dos seus pecúlios, e quem se encarregava de remeter ao senhor os vinte mil-réis mensais. Abriu-lhe logo uma conta corrente, e a quitandeira, quando precisava de dinheiro para qualquer coisa, dava um pulo até à venda e recebia-o das mãos do vendeiro, de "Seu João", como ela dizia. Seu João debitava metodicamente essas pequenas quantias num caderninho, em cuja capa de papel pardo lia-se, mal escrito e em letras cortadas de jornal: "Ativo e passivo de Bertoleza". ${ }^{21}$

O tom pragmático do trecho acima sugere uma relação tripartida através da economia, da lei e da amizade, representada por meio do aconselhamento financeiro. No centro desta equação está a lógica da confiança, estabelecida entre João Romão e Bertoleza:

E por tal forma foi o taverneiro ganhando confiança no espírito da mulher, que esta afinal nada mais resolvia só por si, e aceitava dele, cegamente, todo e qualquer arbítrio. Por último, se alguém precisava

19 Idem, ibidem, p. 224.

20 Georg Simmel, em seu livro The philosophy of money (1900), afirma que os casamentos por dinheiro "are particularly common among primitive groups and conditions where they do not cause any offence at all". Para Simmel, atualmente, há um sentido de dignidade que "arises to every marriage that is not based on personal affection - so that a sense of decency requires the concealment of economic motives". (SIMMEL, Georg. The philosophy of money. Trad. Tom Bottomore e David Frisby. London: Routledge, 1990. p. 380).

21 AZEVEDO, Aluísio. op. cit. p. 20. 
tratar com ela qualquer negócio, nem mais se dava ao trabalho de procurá-la, ia logo direito a João Romão. ${ }^{22}$

Por que ela confia nele? O amor talvez seja a resposta. Contudo, seria o amor a única resposta à confiança cega dela por ele?

Na lógica naturalista isso é explicado pelo desejo de Bertoleza por uma raça superior, como o narrador sugere: "Bertoleza não queria sujeitar-se a negros e procurava instintivamente o homem numa raça superior à sua" ${ }^{23}$. A questão é, dir-se-ia, crucial à lógica da economia, em que a crença, confiança e dependência são fundamentais para o crescimento econômico, como afirmam Paul J. Zak e Stephen Knack em seus estudos sobre o papel da confiança na economia e nas interações sociais ${ }^{24}$. Fica claro para o leitor que a motivação de João é somente o interesse, o lucro financeiro, no qual sua companheira é apenas uma moeda de troca, e Bertoleza permanece presa na sua condição de escrava: do seu antigo dono para o novo maridoadvogado-empresário.

Desse modo, seu novo dono tem-lhe acesso como "marido/amante", acesso ao seu corpo social como escrava transformada em empregada, e ao seu corpo econômico, regulado pelos empréstimos. No entanto, a confiança em João Romão se quebra no final do romance, quando ele é forçado pela lei a devolver Bertoleza aos herdeiros do seu antigo dono. Diante dessa situação, a escrava escolhe a morte:

Reconheceu logo o filho mais velho do seu primitivo senhor, e um calafrio percorreu-lhe o corpo. Num relance de grande perigo compreendeu a situação; adivinhou tudo com a lucidez de quem se vê perdido para sempre; adivinhou que tinha sido enganada; que a sua carta de alforria era uma mentira, e que o seu amante, não tendo coragem para matá-la, restituía-a ao cativeiro. (...)

Bertoleza então, erguendo-se com ímpeto de anta bravia, recuou de um salto e, antes que alguém conseguisse alcançá-la, já de um só golpe certeiro e fundo rasgara o ventre de lado a lado. ${ }^{25}$

O universo de Bertoleza reduz-se a duas escolhas: tornar-se escrava livre e ser parte do novo sistema econômico, no qual o capitalismo está apenas emergindo ou se manifesta na sua forma mais primitiva de acumu-

22 Idem, ibidem, p. 20.

23 Idem.

24 ZAK, Paul J.; KNACK, Stephen. Trust and growth. Royal Economic Society Economic Journal. 111:470 (2001), p. 295-321.

25 AZEVEDO, Aluísio. op. cit. p. 266.

$6 I$

revista ieb $n_{54} 2012$ set./mar. p. 53-66 
lação, representado por João Romão; ou voltar à antiga ordem da escravidão, representada pelo reclamo dos herdeiros do seu antigo senhor ${ }^{26}$.

No seu excelente artigo, Lúcia Sá estudou a produção do espaço em $O$ cortiço e salientou como no romance a população do cortiço mostra "a new free working force that was slowly replacing slave labor in the few years that preceded Abolition". A crítica afirma que "The novel gives a clear view of the relationship between the tenement and the new economic conditions that are producing urban sprawl" ${ }^{27} \mathrm{Em}$ consonância com a análise materialista e histórica de Candido sobre $O$ cortiço, o artigo de Sá chama a atenção para as transformações sociais que estavam acontecendo na cidade do Rio de Janeiro, por volta do último quartel do século XIX. Nesse sentido, o capital é visto como uma força atrás da criação do espaço e da dinâmica social que dele nasce. Dentro dessa perspectiva, vale lembrar Marx, para quem "Circulation is an inescapable condition for capital, a condition posited by its own nature, since circulation is the passing of capital through the various conceptually determined moments of its necessary metamorphosis - its life process" ${ }^{28}$. Assim, uma vez em circulação, o capital está constantemente se transformando, se metamorfoseando. Esta é uma visão também compartilhada por Braudel, para quem o dinheiro é o agente da economia de mercado. O capital acelera a troca e cria uma rede de comércio entre os habitantes da cidade. Braudel enfatiza que as cidades somente existem por causa do dinheiro, e os dois são responsáveis pela fabricação da modernidade. Para ele, a modernidade é entendida como "the changing mass of men's lives - promoted the expansion of money and led to the growing tyranny of the cities"29. A expansão do dinheiro em $O$ cortiço tem início com uma pequena venda até um grande

26 Candido atesta que "A originalidade do romance de Aluísio está nessa coexistência íntima do explorado e do explorador, tornada logicamente possível pela própria natureza elementar da acumulação num país que economicamente ainda era semicolonial”. (CANDIDO, Antonio. op. cit. p. 113).

27 SÁ, Lucia. op. cit.

28 MARX, Karl. Grundrisse. op. cit. p. 658. Marx também afirma que "The circulation of money, regarded for itself, necessarily becomes extinguished in money as a static thing. The circulation of capital constantly ignites itself anew, divides into its different moments, and is a perpetuum mobile" (Idem. p. $5^{16}$ ).

29 Segundo Fernand Braudel, "The truth is that money and cities have always been a part of daily routine, yet they are present in the modern world as well. Money is a very old invention, if one subsumes under that name every means by which exchange is accelerated. And without exchange, there is no society. Cities, too, have existed since prehistoric times. They are multicenturied structures of the most ordinary way of life. But they are also multipliers, capable of adapting to change and helping to bring it about. One might say that cities and money created modernity; but conversely, according to George Gurvitch's law of reciprocity, modernity - the changing mass of men's lives - promoted the expansion of money and led to the growing tyranny of the cities. Cities and money are at one and the same time motors and indicators; they provoke and indicate change". (BRAUDEL, Fernand. Afterthoughts on material civilization and capitalism. Trad. Patricia M. Ranum. Baltimore: The Johns Hopkins Press, 1977. p. 15). 
bazar, de um complexo de pequenas casinhas até o grande complexo habitacional do cortiço, das pequenas ruas até a grande avenida, e, por fim, a incorporação do subúrbio de Botafogo à cidade do Rio de Janeiro, como Sá sugere no seu artigo. No romance isso é ilustrado na passagem:

E, assim como este, notavam-se por último na estalagem muitos inquilinos novos, que já não eram gente sem gravata e sem meias. A feroz engrenagem daquela máquina terrível, que nunca parava, ia já lançando os dentes a uma nova camada social que, pouco a pouco, se deixaria arrastar inteira lá para dentro. Começavam a vir estudantes (...) surgiram contínuos de repartições públicas, caixeiros de botequim, artistas de teatro, condutores de bondes, e vendedores de bilhetes de loteria. (...) italianos (...). O prédio do Miranda parecia ter recuado alguns passos, perseguido pelo batalhão das casinhas da esquerda, e agora olhava a medo, por cima dos telhados, para a casa do vendeiro, que lá defronte erguia-se altiva, desassombrada, o ar sobranceiro e triunfante. João Romão conseguira meter o sobrado do vizinho no chinelo (...). Foi abaixo aquele grosso e velho muro da frente com o seu largo portão de cocheira, e a entrada da estalagem era agora dez braças mais para dentro, tendo entre ela e a rua um pequeno jardim com bancos e um modesto repuxo ao meio, de cimento, imitando pedra. Fora-se a pitoresca lanterna de vidros vermelhos; foram-se as iscas de fígado e as sardinhas preparadas ali mesmo à porta da venda sobre as brasas; $\mathrm{e}$ na tabuleta nova, muito maior que a primeira, em vez de "Estalagem de São Romão" lia-se em letras caprichosas: "AVENIDA SÃO ROMÃO”. ${ }^{30}$

\section{Dinheiro e distinção}

No final do romance, por um instante, a morte súbita e trágica de Bertoleza choca João Romão. Porém, seu momento de tristeza é substituído pelo título que lhe é dado pelas autoridades, com o qual Azevedo com um tom sarcástico termina o romance: "Nesse momento parava à porta da rua uma carruagem. Era uma comissão de abolicionistas que vinha, de casaca! trazer-lhe respeitosamente o diploma de sócio benemérito" 31 .

Esse desfecho ficcional confirma o que Marx escreveu sobre o poder do dinheiro: "I am bad, dishonest, unscrupulous, stupid; but money is honoured, and hence its possessor. Money is the supreme good, therefore its possessor

3o AZEVEDO, Aluísio. op. cit. p. 238-239.

31 Idem, ibidem, p. 266-267.

63

revista ieb $n_{54} 2012$ set./mar. p. 53-66 
is good"32. O título de distinção que é conferido a João Romão nos leva a outra dimensão na dinâmica do capitalismo. Como o narrador o expressa, a excitação do avarento se perde quando a acumulação do dinheiro se torna um fim em si mesmo: "sua impotência para pretender outra coisa que não fosse ajuntar dinheiro, e mais dinheiro, e mais ainda, sem saber para que e com que fim, acabaram azedando-lhe de todo a alma e tingindo de fel a sua ambição e despolindo o seu ouro". A ambição de João Romão pela distinção emerge no momento em que seu vizinho rico, Miranda, recebe o título de barão. O desejo de posse de coisas materiais é agora substituído pelo simbólico, o que as coisas representam, traduzido como inveja:

Sim, senhor! aquele taverneiro, na aparência tão humilde e tão miserável; aquele sovina que nunca saíra dos seus tamancos e da sua camisa de riscadinho de Angola; aquele animal que se alimentava pior que os cães, para pôr de parte tudo, tudo, que ganhava ou extorquia; aquele ente atrofiado pela cobiça e que parecia ter abdicado dos seus privilégios e sentimentos de homem; aquele desgraçado, que nunca jamais amara senão o dinheiro, invejava agora o Miranda (...)..$^{53}$

A rápida transformação de João Romão de avarento, de pequeno comerciante a rentier não é suficiente. Para o "futuro visconde" ou barão, o dinheiro não era tudo. Além disso, ele tinha outros sonhos:

uma vida fidalga, de muito luxo, de muito dinheiro; uma vida de palácio, entre mobílias preciosas e objetos esplêndidos, onde ele se via cercado de titulares milionários... E ali ele não era, nunca fora, o dono de um cortiço, de tamancos e em mangas de camisa; ali era o Sr. Barão! O Barão do ouro! o Barão das grandezas! o Barão dos milhões! ${ }^{54}$

Não mais o dono da vendinha, mas o "famoso, o enorme capitalista! o proprietário sem igual! o incomparável banqueiro" ${ }^{35}$. No entanto, a distinção tem um preço, e João Romão tem ciência disso, dado que ele precisaria colocar de volta o dinheiro em circulação: "Teria gasto mais, é verdade!... Não estaria tão bem!... mas, ora adeus! estaria habilitado a fazer do meu dinheiro o que bem quisesse!... Seria um homem civilizado!”36; a distinção social é aqui equiparada à civilização. E isto significa uma mudança na visão da existência e no modo de gerir dinheiro de João Romão. Avarento

32 MARX, Karl. Economic and philosophic manuscripts of I844. op. cit.

33 AZEVEDO, Aluísio. op. cit. p. 136.

34. Idem, ibidem, p. 138.

35 Idem.

36 Idem, ibidem, p. 140. 
no passado, ele agora se torna um gastador com intuito de obter distinção: "Mandou fazer boas roupas e aos domingos refestelava-se de casaco branco e de meias, assentado defronte da venda, a ler jornais" ${ }^{\prime 3}$. De fato, dentro da perspectiva de João Romão gastar dinheiro é também uma forma de lucro, por meio do capital simbólico que a distinção representa. As ações de João Romão, se transferem para os bens materiais; como Pierre Bourdieu assinala, a "economia dos bens culturais"38. É interessante destacar nesse sentido como a própria concepção de tempo para João Romão muda. Se o tempo para ele, no começo do romance, era definido somente pelo trabalho, pela produção e pela acumulação do capital, agora o tempo é dedicado a um conceito não produtivo de tempo; por exemplo, o lazer "a ler jornais". Sua transformação passa a ser também física: "Depois deu para sair a passeio, vestido de casimira, calçado e de gravata. Deixou de tosquiar o cabelo à escovinha; pôs a barba abaixo, conservando apenas o bigode"39. Uma mudança completa no estilo de vida que implica tomar lições de dança, decorar a casa, tomar vinho, aprender regras de etiqueta, frequentar teatro e ler literatura francesa em tradução.

Georg Simmel estuda a relação entre o dinheiro e distinção social. No seu livro Philosophy of money, ele discute a relação entre dinheiro e individualidade e afirma: "we value the distinct formation of individuality, the mere fact that a personality possesses a specific and concise form and power" ${ }^{\prime 40}$. Simmel observa que posses têm um grande poder de influência e distinção, e de algum modo definem a individualidade. Para ele, ao possuir ou ter " a power of disposal over objects enters into the circle of our Ego. The Ego, our desires andfeelings, continues to live in the objects we own"41. O que liga a individualidade ao dinheiro é entendido através da ótica da psicologia. $\mathrm{O}$ autor afirma que a distinção revela resistência "of being interchangeable, of the reduction to a common denominator and of 'common activity". É interessante observar como Simmel liga a definição de distinção social ao discurso econômico e matemático. Assim, a distinção resiste àquilo que é característico de uma mercadoria ${ }^{42}$. Segundo ele, "distinction should not be so conspicuous as to entice what is distinguished away from its independence, its reserve and its inner self-containment and to transpose its essence

37 Idem, ibidem, p. 177 .

38 BOURDIEU, Pierre. Distinction: A social critique of the judgement of taste. Trad. Richard Nice. Cambridge, Massachusetts: Harvard University Press, 1984.

39 Idem.

40 SIMMEL, Georg. op. cit. p. 390 .

41 Idem, ibidem, p. 389 .

42 Marx define a commodity como "an object outside us, a thing that by its properties satisfies human wants of some sort or another". (MARX, Karl. Capital. Vol. 1, Part I: Commodities and money (1867). Disponível em: <http://www.marxists.org/archive/marx/works/1867cı/choı.htm $\#$ Si $>$. Acesso em 5 jul. 2010. 
into a relationship to others, be it only a relationship of difference". Dentro desta perspectiva, a distinção se destaca devido às suas características de exclusividade e de diferenciação, visto que "The distinguished person is the very person who completely reserves his personality. Distinction represents a quite unique combination of senses of differences that are based upon and yet reject any comparison at all" ${ }^{35}$.

Vamos concluir por dizer que para João Romão, no fim, distinção não implica renunciar ao dinheiro. Antes da mudança no seu estilo de vida, ele sonhava em ser reconhecido como "o famoso, o enorme capitalista! o proprietário sem igual! o incomparável banqueiro" "44. Seu ideal pela distinção também muda a dinâmica do capital: "Admitiu mais três caixeiros; já não se prestava muito a servir pessoalmente à negralhada da vizinhança, agora até mal chegava ao balcão" ${ }^{\text {"5 }}$. Desse modo, o dinheiro encontra uma lógica diferente e estabelece uma nova dinâmica no cortiço:

E em breve o seu tipo começou a ser visto com frequência na Rua Direita, na praça do comércio e nos bancos, o chapéu alto derreado para a nuca e o guarda-chuva debaixo do braço. Principiava a meter-se em altas especulações, aceitava ações de companhias de títulos ingleses e só emprestava dinheiro com garantias de boas hipotecas. ${ }^{46}$

$O$ cortiço foi escrito numa época em que a literatura estava ligada ao método naturalista, ao qual o romance mantém sua dívida. Como em toda tradição da ficção naturalista, influenciada pela escola de Zola, Azevedo tenta fazer uma crítica coerente e científica da realidade corrompida. Em vista disso, João Romão torna-se um vilão, interessado somente em explorar o fraco com o intuito de vencer, validando a máxima darwinista da sobrevivência do mais forte em termos da lógica da economia. Não é por acaso que $o$ autor denuncia o protagonista e seu comportamento como uma "moléstia nervosa, uma loucura, um desespero de acumular". Dentro dessa perspectiva, o avarento, o empresário seminal transformado em rentier, no fim se torna um financiador e especulador. Em resumo, $O$ cortiço é o Bildungsroman de um capitalista.

43 SIMMEL, Georg. op. cit. p. 39o. No entanto, Simmel salienta que a tendência de distinção é desaparecer na dinâmica e no desenvolvimento do capitalismo, uma vez que objetos são produzidos com base no seu valor monetário: "Yet the more money dominates interests and sets people and things into motion, the more objects are produced for the sake of money and are valuated in terms of money, the less can the value of distinction be realized in men and in objects" (p. 390-391).

44 AZEVEDO, Aluísio. op. cit. p. 95.

45 Idem, ibidem, p. 178.

46 Idem.

revista ieb $n_{54} 2012$ set./mar. p. 53-66 